\title{
Vicisitudes de los compromisos comerciales internacionales de Colombia
}

Fabián Enrique Vilar-Rubiano*

Especialista en Contratación Internacional y candidato a Magíster en Integración y Globalización. Profesor, Universidad Externado de Colombia, Bogotá, Colombia.

Correo electrónico:

fabian.vilar@uexternado.edu.co

Recibido: 26 de mayo del 2015

Aprobado: 12 de julio del 2015

Cómo citar este artículo: Fabián Enrique Vilar-Rubiano. Vicisitudes de los compromisos comerciales internacionales de Colombia. DIXI 22. Pág. 37. Diciembre 2015. doi: http:// dx.doi.org/10.16925/di.v17i22.1241

\section{Resumen}

Propósito: en la última década, Colombia ha orientado su política pública de integración económica hacia la celebración intensiva de tratados internacionales de naturaleza comercial que conlleva la generación de derechos y la asunción de obligaciones a nivel interno e internacional; en consecuencia, cada vez cobra mayor importancia la manera como el Estado colombiano da cumplimiento a las obligaciones comerciales internacionales derivadas de la implementación de los Tratados de Libre Comercio (TLC) en vigor para Colombia. Descripción: este artículo aborda el análisis de los inconvenientes cuando se presentan en el ámbito de la incorporación de los TLC al ordenamiento jurídico interno. Punto de vista: este asunto eventualmente puede llegar a afectar a Colombia en el escenario internacional y su política comercial en los últimos años, como consecuencia del proceso de honrar el principio de pacta sunt servanda del Derecho internacional en el marco de los TLC. Conclusiones: de esta manera, se acude a la hermenéutica para examinar la jurisprudencia de la Corte Constitucional cuando ha dispuesto declarar inconstitucional asuntos que están íntimamente relacionados con los TLC, convirtiéndose en verdaderas vicisitudes de los compromisos comerciales internacionales que Colombia debe afrontar.

Palabras clave: Corte Constitucional, implementación, integración económica, Tratado de Libre Comercio, obligaciones comerciales internacionales. 


\title{
Vicissitudes of International Trade Commitments by Colombia
}

\begin{abstract}
Purpose: Over the last decade, Colombia has concentrated its public policy for economic integration through intensive signature of international trade treaties that lead to the generation of rights and the acquisition of obligations, both internally and internationally. Therefore, the way in which the Colombian State fulfills the international trade obligations deriving from the Free Trade Agreements (FTA) in force in Colombia becomes ever more important. Description: This article deals with the analysis of problems that can arise in the realm of incorporation of these FTAs into the internal legal system. Point of view: This aspect could affect Colombia on the international stage and in relation to its trading policy in recent years, because of the process of honoring the principle of pacta sunt servanda in international law in the framework of the FTAs. Conclusions: In this way, hermeneutics are used to examine the jurisprudence of the Constitutional Court when it has ruled certain aspects that are intimately related to the FTAS as unconstitutional, making them true vicissitudes for the international trade commitments that Colombia must face.
\end{abstract}

Keywords: Constitutional Court, implementation, economic integration, Free Trade Agreement, international trade obligations.

\section{Vicissitudes dos compromissos comerciais internacionais da Colômbia}

\section{Resumo}

Propósito: na última década, a Colômbia orientou a sua política pública de integração econômica para a celebração intensiva de tratados internacionais de natureza comercial que leva à geração de direitos e à aceitação de obrigações a nível interno e internacional; como consequência, cada vez mais cresce a importância de como o Estado colombiano cumpre as obrigações comerciais internacionais derivadas da implementação dos Tratados de Livre Comércio (TLC) em vigor para a Colômbia. Descrição: este artigo aborda a análise dos inconvenientes quando estes aparecem no âmbito da incorporação dos TLC ao sistema jurídico interno. Ponto de vista: esse assunto eventualmente pode chegar a afetar a Colômbia no cenário internacional e sua política comercial nos últimos anos, como consequência do processo de honrar o princípio de pacta sunt servanda do Direito internacional no marco dos TLC. Conclusões: dessa maneira, recorre-se à hermenêutica para examinar a jurisprudência da Corte Constitucional quando declarou inconstitucional assuntos que estão intimamente relacionados com os TLC, convertendo-se em verdadeiras vicissitudes dos compromissos comerciais internacionais que a Colômbia deve enfrentar.

Palavras-chave: Corte Constitucional, implementação, integração econômica, Tratado de Livre Comércio, obrigações comerciais internacionais. 


\section{CONSIDERACIONES PRELIMINARES ${ }^{1}$}

En los años recientes el Ministerio de Comercio, Industria y Turismo de Colombia (Minciт) en asuntos de comercio exterior ha mostrado una marcada tendencia a priorizar la vinculación del Estado en numerosos acuerdos de naturaleza comercial —en su mayoría bilaterales-, con el propósito de profundizar la integración económica y buscar nuevos mercados para los productos y servicios colombianos. En particular, de esta clase Colombia tiene en vigor diez acuerdos, ${ }^{2} \mathrm{y}$ aspira a que en el futuro cercano entren en vigor otros siete. ${ }^{3}$

Un tratado internacional, luego de ser suscrito, para entrar en vigor debe adelantar el proceso de incorporación al Derecho interno, de manera que en el caso colombiano intervienen todas las ramas del poder público ${ }^{4}$ con el fin de garantizar un adecuado balance en su trámite.

\section{A. Implementación}

Además del compromiso de Colombia de obtener la aprobación de los TLC, surgen otras obligaciones internacionales adicionales para el país, consistentes en vincularse a determinados tratados internacionales, ${ }^{5} \mathrm{o}$ bien estos requieren regulación en el ordenamiento jurídico interno. Este procedimiento de cumplimiento se denomina implementación.

En la implementación de los TLC se identifican y clasifican las obligaciones por temas, ${ }^{6}$ se establece si ya se cumplieron o se determina su estado en caso de estar pendiente su observancia. Respecto a los compromisos por cumplir, se determina su plazo y la figura normativa que corresponde (ley, decreto, resolución, circular u otro), a la cual es necesario monitorear hasta lograr darle cumplimiento.

A fin de observar las obligaciones comerciales internacionales de Colombia generadas con el proceso de implementación, recientemente el Mincit ha impulsado la creación de las siguientes normas, las cuales se exponen en la tabla 1 .

Tabla 1. Implementación de obligaciones comerciales internacionales desde 2012

\begin{tabular}{|l|l|l|}
\hline \multicolumn{1}{|c|}{ Fecha } & \multicolumn{1}{|c|}{ Norma } & \multicolumn{1}{c|}{ Tema } \\
\hline Enero 12 del 2012 & Decreto 28 & $\begin{array}{l}\text { Compromisos arancelarios del Acuerdo de Libre Comercio (ALC) con los Estados AELC en } \\
\text { el sector automotor }\end{array}$ \\
\hline Enero 12 del 2012 & Decreto 29 & Compromisos arancelarios del ALC con los Estados AELC \\
\hline Enero 30 del 2012 & Decreto 185 & Compromisos arancelarios del ALC con Canadá \\
\hline Enero 30 del 2012 & Decreto 186 & Compromisos arancelarios del ALC con Canadá \\
\hline Marzo 21 del 2012 & Decreto 573 & Medidas de Salvaguardia Especial Agrícola (sEA) \\
\hline Febrero del 2012 & Ley 1515 & $\begin{array}{l}\text { Aprobatoria del Tratado de Budapest sobre el reconocimiento internacional del depósito de } \\
\text { microorganismos a los fines del procedimiento en materia de Patentes }\end{array}$ \\
\hline Abril 13 del 2012 & Ley 1518 & $\begin{array}{l}\text { Aprobatoria del convenio internacional para la Protección de las Obtenciones Vegetales } \\
\text { (UPov 91) }\end{array}$ \\
\hline Abril 13 del 2012 & Ley 1519 & $\begin{array}{l}\text { Aprobatoria del convenio sobre la distribución de señales portadoras de programas trans- } \\
\text { mitidas por satélite (Bruselas) }\end{array}$ \\
\hline
\end{tabular}

1. Las opiniones expresadas en este artículo corresponden exclusivamente al autor y no representan la posición oficial de la entidad para la cual presta sus servicios profesionales.

2. Tales como los celebrados con Nicaragua, México, Cuba, Chile, el Triángulo Norte de Centroamérica (El Salvador, Guatemala y Honduras); la Asociación Europea de Libre Comercio (AELC): Suiza, Noruega, Islandia y Liechtenstein; Canadá, Estados Unidos, Venezuela y la Unión Europea (UE).

3. Estos con Corea del Sur, la Alianza del Pacífico (AP): Chile, Colombia, México y Perú; Costa Rica, Panamá e Israel (suscritos); así como Turquía y Japón (en negociación).
4. La rama ejecutiva suscribe el tratado -artículo 189 numeral 2 Constitución Política de Colombia (CP) y artículo 7 de la Convención de Viena sobre el Derecho de los Tratados (Cv) - , el Congreso lo aprueba mediante una ley —artículo 150 numeral $16 \mathrm{cP}$ - y la rama judicial realiza por conducto de la Corte Constitucional un examen de constitucionalidad del tratado y su ley aprobatoria — artículo 241 numeral $10 \mathrm{CP}-$.

5. Verbigracia acuerdos internacionales en materia de propiedad intelectual.

6. La clasificación se da de esta manera: Obstáculos Técnicos al Comercio (отс); Acceso Agrícola; Acceso no Agrícola; Salvaguardias (sG); Reglas de Origen (RO); Facilitación al Comercio; Servicios; Compras Públicas; Propiedad Intelectual (PI); Laboral y Ambiental. 
Cont.

\begin{tabular}{|c|c|c|}
\hline Abril 13 del 2012 & Ley 1520 & Implementación del Acuerdo de Promoción Comercial (APC) con Estados Unidos \\
\hline Abril 13 del 2012 & Decreto 727 & Datos de prueba de agroquímicos \\
\hline Abril 13 del 2012 & Decreto 728 & Contingente de cuartos traseros de pollo y arroz \\
\hline Abril del 2012 & Decreto 729 & Marcas y patentes \\
\hline Abril 13 del 2012 & Decreto 730 & Cumplimiento a los compromisos adquiridos en el APC con Estados Unidos \\
\hline Abril 13 del 2012 & Decreto 731 & Medidas de salvaguardia textil \\
\hline Abril 13 del 2012 & Decreto 733 & Transparencia en la solicitud de registros sanitarios y evaluaciones \\
\hline Abril 13 del 2012 & Decreto 735 & $\begin{array}{l}\text { Prohibición del ingreso a Colombia de aves provenientes de zonas que hayan registrado } \\
\text { influenza aviar }\end{array}$ \\
\hline Mayo 11 del 2012 & Circular 23 & $\begin{array}{l}\text { Procedimiento para la aplicación de medidas de salvaguardia especial agrícola convenidas } \\
\text { en los acuerdos comerciales internacionales vigentes para Colombia }\end{array}$ \\
\hline Mayo 15 del 2012 & Decreto 993 & Promulgación del APC con Estados Unidos \\
\hline Agosto 28 del 2012 & Circular 39 & Distribución y administración del contingente de azúcar en el APC con Estados Unidos \\
\hline Septiembre 6 del 2012 & Decreto 1860 & Aplicación provisional al Acuerdo de Alcance Parcial (AAP) con Venezuela \\
\hline Octubre 18 del 2012 & Circular 42 & $\begin{array}{l}\text { Distribución y administración del contingente de azúcar otorgado por Estados Unidos a } \\
\text { Colombia en el marco de la Organización Mundial del Comercio (oMc) }\end{array}$ \\
\hline Octubre 18 del 2012 & Circular 43 & Reasignación del contingente de azúcar en el APC con Estados Unidos \\
\hline $\begin{array}{l}\text { Noviembre } 22 \text { del } \\
2012\end{array}$ & Circular 50 & $\begin{array}{l}\text { Actualización de la lista de productos que requieren vistos buenos para la presentación de } \\
\text { solicitudes de registro y de licencia de importación }\end{array}$ \\
\hline Diciembre 27 del 2012 & Circular 52 & Adición de vistos buenos a la lista de productos del anexo 12 de la Circular 50 del 2012 \\
\hline Julio 12 del 2013 & Ley 1648 & Establece medidas de observancia a los derechos de propiedad industrial \\
\hline Julio 18 del 2013 & Decreto 1513 & $\begin{array}{l}\text { Aplicación provisional al acuerdo comercial entre Colombia y el Perú } \\
\text { Aplicación provisional al acuerdo comercial entre Colombia, la UE y sus Estados Miembros }\end{array}$ \\
\hline Julio 31 del 2013 & Decreto 1636 & $\begin{array}{l}\text { Implementa compromisos de acceso a mercados en virtud del acuerdo comercial entre } \\
\text { Colombia y el Perú, por una parte, y la uE y sus Estados Miembros, por otra }\end{array}$ \\
\hline Agosto 21 del 2013 & Decreto 1789 & Se impone una medida especial a las importaciones de aceites \\
\hline Octubre 8 del 2013 & Decreto 2211 & $\begin{array}{l}\text { Medidas de salvaguardia provisional a las importaciones de barras de hierro o acero sin } \\
\text { alear (barras corrugadas), originarias de países miembros de la OMC }\end{array}$ \\
\hline Octubre 8 del 2013 & Decreto 2212 & $\begin{array}{l}\text { Medidas de salvaguardia provisional a las importaciones de barras de hierro o acero sin } \\
\text { alear (alambrones corrugados), originarias de países miembros de la oMC }\end{array}$ \\
\hline Octubre 8 del 2013 & Decreto 2213 & $\begin{array}{l}\text { Medidas de salvaguardia provisional a las importaciones de alambrón de acero, originarias } \\
\text { de países miembros de la OMC }\end{array}$ \\
\hline Octubre 16 del 2013 & $\begin{array}{l}\text { Directiva Pre- } \\
\text { sidencial N. }{ }^{\circ} 8 \\
\text { de } 2013\end{array}$ & $\begin{array}{l}\text { Coordina la participación del Gobierno Nacional en el trámite de leyes aprobatorias de acuer- } \\
\text { dos comerciales internacionales, su implementación legal y control de constitucionalidad }\end{array}$ \\
\hline Febrero 19 del 2014 & Decreto 332 & Modifica parcialmente el Arancel de Aduanas \\
\hline Febrero 28 del 2014 & Decreto 456 & Modifica parcialmente el Arancel de Aduanas \\
\hline Marzo 14 del 2014 & Decreto 555 & Modifica parcialmente el Arancel de Aduanas \\
\hline
\end{tabular}

Fuente: elaboración propia

\section{B. Análisis de constitucionalidad (vicisitudes)}

La regla general es que tanto los TLC, como su implementación, no tienen inconveniente alguno a nivel de Derecho interno. No obstante, algunas veces la
Corte Constitucional ha emitido sentencias que van en contravía de este propósito, convirtiéndose en verdaderas vicisitudes para el cabal cumplimiento de los compromisos comerciales internacionales de Colombia (tabla 2). 
Tabla 2. Sentencias que constituyen vicisitudes de los compromisos comerciales internacionales de Colombia

\begin{tabular}{|c|c|c|c|}
\hline Fecha & Sentencia & Ponente & Decisión \\
\hline $\begin{array}{l}\text { Noviembre } \\
24 \text { del } 2010\end{array}$ & $\begin{array}{l}\text { C-941 } \\
\text { de } 2010\end{array}$ & $\begin{array}{l}\text { Jorge Iván } \\
\text { Palacio Palacio }\end{array}$ & $\begin{array}{l}\text { Declara inexequible el Memorando de Entendimiento relativo al Acuerdo de Libre } \\
\text { Comercio entre la República de Colombia y los Estados de la AELC }\end{array}$ \\
\hline $\begin{array}{l}\text { Diciembre } \\
5 \text { del } 2012\end{array}$ & $\begin{array}{l}\text { C-1051 } \\
\text { de } 2012\end{array}$ & $\begin{array}{l}\text { Luis Guillermo } \\
\text { Guerrero Pérez }\end{array}$ & $\begin{array}{l}\text { Declara inexequible la Ley } 1518 \text { del } 13 \text { de abril de } 2012 \text {. "Por medio de la cual e aprueba } \\
\text { el Convenio Internacional para la Protección de Obtenciones Vegetales, del } 2 \text { de diciem- } \\
\text { bre de } 1961 \text {, revisado en Ginebra el } 10 \text { de noviembre de 1972, el } 23 \text { de noviembre de } \\
1978 \text { y el } 19 \text { de marzo de } 1991 \text { " }\end{array}$ \\
\hline $\begin{array}{l}\text { Enero } 23 \\
\text { del } 2013\end{array}$ & $\begin{array}{l}\text { C-011 } \\
\text { de } 2013\end{array}$ & $\begin{array}{l}\text { Alexei Julio } \\
\text { Estrada }\end{array}$ & $\begin{array}{l}\text { Declara inexequible la Ley } 1520 \text { de } 2012 \text {. "Por medio de la cual se implementan com- } \\
\text { promisos adquiridos por virtud del Acuerdo de Promoción Comercial suscrito entre la } \\
\text { República de Colombia y los Estados Unidos de América y su Protocolo Modificatorio, } \\
\text { en el marco de la política de comercio exterior e integración económica" }\end{array}$ \\
\hline $\begin{array}{l}\text { Enero } 23 \\
\text { del } 2013\end{array}$ & $\begin{array}{l}\text { C-014 } \\
\text { de } 2013\end{array}$ & $\begin{array}{l}\text { María Victoria } \\
\text { Calle Correa }\end{array}$ & $\begin{array}{l}\text { Declara estarse a lo resuelto en la sentencia C- } 011 \text { de } 2013 \text {, mediante la cual se declaró } \\
\text { inexequible la Ley } 1520 \text { de } 2012 \text {, de la cual hacen parte los artículos } 13 \text { y } 14 \text { demandados } \\
\text { en este proceso }\end{array}$ \\
\hline $\begin{array}{l}\text { Febrero } 13 \\
\text { del } 2013\end{array}$ & $\begin{array}{l}\text { C-069 } \\
\text { de } 2013\end{array}$ & $\begin{array}{l}\text { Jorge Ignacio } \\
\text { Pretelt Chaljub }\end{array}$ & $\begin{array}{l}\text { Declara estarse a lo resuelto en la sentencia C-011 de 2013, mediante la cual se declaró } \\
\text { inexequible la Ley } 1520 \text { de } 2012\end{array}$ \\
\hline $\begin{array}{l}\text { Marzo } 6 \\
\text { del } 2013\end{array}$ & $\begin{array}{l}\text { C-109 } \\
\text { de } 2013\end{array}$ & $\begin{array}{l}\text { Jorge Ignacio } \\
\text { Pretelt Chaljub }\end{array}$ & $\begin{array}{l}\text { Declara estarse a lo resuelto en la sentencia C-011 de 2013, mediante la cual se declaró } \\
\text { inexequible la Ley } 1520 \text { de } 2012\end{array}$ \\
\hline $\begin{array}{l}\text { Junio } 19 \\
\text { del } 2013\end{array}$ & $\begin{array}{l}\text { C-350 } \\
\text { de } 2013\end{array}$ & $\begin{array}{l}\text { Mauricio Gon- } \\
\text { zález Cuervo }\end{array}$ & $\begin{array}{l}\text { Declara que El Gobierno Nacional sólo podrá realizar el depósito del instrumento de } \\
\text { adhesión al presente tratado, acompanándolo de la siguiente declaración interpretativa } \\
\text { respecto a los artículos } 3 \text {, numeral } 1 \text {, literal a y } 5 \text { : "El acceso al material biológico objeto } \\
\text { de depósito regulado en el presente Tratado, su salida del país y el reconocimiento de } \\
\text { la respectiva patente deberán realizarse de conformidad con las protecciones previstas } \\
\text { en el régimen constitucional colombiano, específicamente, en los artículos } 8 \text {, 58, inciso } \\
\text { segundo, } 81 \text {, inciso segundo y } 330 \text { de la Constitución Política" }\end{array}$ \\
\hline $\begin{array}{l}\text { Abril } 23 \\
\text { del } 2014\end{array}$ & $\begin{array}{l}\text { C-258 } \\
\text { de } 2014\end{array}$ & $\begin{array}{l}\text { María Victoria } \\
\text { Calle Correa }\end{array}$ & $\begin{array}{l}\text { Declara inexequible la Ley } 1628 \text { de } 2013 \text { por medio de la cual se aprueba el acuerdo } \\
\text { marco de la AP }\end{array}$ \\
\hline
\end{tabular}

Fuente: elaboración propia

En consecuencia, de las ocho sentencias enunciadas, se seleccionaron cinco casos (temas) cuyos efectos se analizarán dado su gran impacto en la política comercial de Colombia.

\section{Memorando De EnTENDimiento}

\section{AELC}

\section{A. Sentencia $C-941 / 10^{7}$}

De acuerdo con lo consignado en el expediente de la sentencia, los temas tratados en esta son:

7. Las normas invocadas o aplicadas en la sentencia son: Artículos 241 numeral 10, 244, 88, 333, 334, 78, 150; numerales $11,12,14$ y 16, 2, 226, 227, 13, 336, 9; Preámbulo, 1, 2, 4, 189 numeral 2, 157, $160,93,15,100,49,65,79,48,53,371$ al 373, 61, 366, 29, 209 y 116 de la CP. Artículos 11 y 50 del Decreto 2067 de 1991; Decreto 4712 de 2007; Artículos 217 y 204 de la Ley 5 de 1992; Artículo 26 de la Cv; Decisión 351 de 1993; Convenio 169 de la Organización Internacional del Trabajo (оIт) y Ley 170 de 1994.
Revisión constitucional del Acuerdo de Libre Comercio entre la República de Colombia y los Estados AELC, el Memorando de Entendimiento relativo al Acuerdo de Libre Comercio entre la República de Colombia y los Estados de la AELC (en adelante el Memorando) y el Canje de Notas respecto del Capítulo 4 del Acuerdo de Libre Comercio entre la República de Colombia y los Estados AELC, suscritos en Ginebra, a los 25 días del mes de noviembre de dos mil ocho; el Acuerdo sobre Agricultura entre la República de Colombia y la Confederación Suiza, hecho en Ginebra, a los 25 días del mes de noviembre de 2008; el Acuerdo sobre Agricultura entre la República de Colombia y la República de Islandia, hecho en Ginebra, a los 25 días del mes de noviembre de 2008; y el Acuerdo sobre Agricultura entre la República de Colombia y el Reino de Noruega, hecho en Ginebra, a los 25 días del mes de noviembre de 2008 y la Ley aprobatoria número 1372 del 7 de enero de 2010. ${ }^{8}$

8. Véase Corte Constitucional de Colombia. Sentencia C-941-10. (M. P. Jorge Iván Palacio Palacio; Noviembre 24 de 2010). 


\section{Hechos relevantes del caso}

El 11 de febrero del 2010, en uso de sus atribuciones establecidas en la Constitución Política (CP), la Corte Constitucional con ponencia del magistrado Jorge Iván Palacio Palacio avocó el conocimiento del proceso de revisión constitucional.

Posterior a la defensa de constitucionalidad presentada en término por el Mincit, la Procuraduría General de la Nación (PGN) ${ }^{9}$ en su intervención manifiesta ${ }^{10}$ - entre otras consideraciones - con respecto al Memorando este no aparece publicado en la gaceta en la que se divulga el proyecto de ley, ni en el Diario Oficial en el cual se publica la Ley 1372 de 2010, de manera que solicita declarar su inexequibilidad.

El Mincit, en respuesta a solicitud de la Corte Constitucional, se pronunció sobre el Concepto de la PGN en relación con el Memorando en los siguientes términos:

a. En el título del proyecto de ley y de la Ley 1372 de 2010, se manifiesta la aprobación del Memorando.

b. En el encabezado de la ley aprobatoria, el Congreso declara haber visto y conocer el Memorando, y en esa medida decreta su aprobación mediante Ley de la República.

c. Los textos se encontraban disponibles en la página web del Mincit, y eran de público conocimiento.

La Corte Constitucional emitióla sentencia C-941 del 24 de noviembre de 2010, declarando inexequibles las referencias a "el Memorando de Entendimiento relativo al Acuerdo de Libre Comercio entre la República de Colombia y los Estados de la AELC", ${ }^{11}$ contenidas en el título y los artículos 1 y 2 de la Ley número 1372 del 7 de enero de 2010.

Finalmente, el Memorando tuvo que repetir trámite de incorporación al Derecho interno, en el cual fue aprobado por la Ley 1513 de 2012 y declarado exequible junto con su ley aprobatoria por la Corte Constitucional, mediante la Sentencia C-714 del 12 de septiembre de 2012 .

\section{Observaciones}

Por un lado, la Sentencia C-941/2010 declaró exequible el ALC, el Canje de Notas respecto al Capítulo 4

\footnotetext{
9. Véase Constitución Política de Colombia [Const]. Art. 278 numeral 5 .

10. Véase Concepto 4999 de 2010. [Procuraduría General de la Nación]. Agosto 2 de 2010.

11. Véase Corte Constitucional de Colombia, supra, nota 8.
}

del tratado y los acuerdos de agricultura con los Estados AELC. Por otro lado, declaró la inconstitucionalidad de las referencias al "Memorando de la Ley 1372 de 2010", al no ser publicado.

Como quiera que el ámbito del presente escrito aborde las vicisitudes que se presentan con algunas providencias judiciales, se comentará exclusivamente lo que fue declarado inexequible. En el caso concreto, el tema se circunscribe al siguiente problema jurídico: ¿Se satisface el trámite legislativo cuando en la publicación de una ley el Congreso manifiesta que su texto ha sido visto y aprobado?

La Corte Constitucional consideró que se presentó un vicio de procedimiento de carácter insaneable, dado que la ausencia de publicación del texto del Memorando se dio desde el momento en que el proyecto de ley inició su trámite legislativo en la Comisión Segunda del Senado, se prolongó en la sanción presidencial y finalmente en la promulgación de la Ley 1372 de 2010, en el Diario Oficial número 47.585 del 7 de enero de 2010. Asimismo, establece que no basta con señalar que se satisface el presupuesto de publicidad con la sola referencia expresa contenida en la ley aprobatoria (título y articulado), toda vez que este principio exige indefectiblemente la publicación del texto del instrumento internacional que se aprueba.

De esta forma, de manera acertada la Corte Constitucional pone de presente los efectos de la omisión de la publicación oficial del proyecto de ley, ${ }^{12}$ así como la trascendencia y necesidad del principio de publicidad en la expedición de la norma como elemento esencial para su validez $y$, por ende, su constitucionalidad.

La publicación oficial e integral del texto de la ley son requisitos que desarrollan los principios de publicidad y transparencia, necesarios en la producción normativa en un Estado Social de Derecho con el fin de garantizar el adecuado conocimiento de las normas, tanto por parte del regulador, como de la sociedad a la cual están destinadas.

En el sistema de pesos y contrapesos del modelo de Estado colombiano, la Corte Constitucional desarrolla un papel muy importante en el control del cumplimiento del trámite legislativo.

Finalmente, es interesante la tesis presentada por el MinciT ${ }^{13}$ al respecto, argumentando que los textos se encontraban disponibles en su página web y que eran de público conocimiento. En este punto

12. Véase Const., supra, nota 9, Art. 157 numeral 1.

13. Cf. Oficio del 19 de octubre de 2010. [Ministerio de Comercio, Industria y Turismo de Colombia]. Octubre 19 de 2010. 
es importante resaltar que si bien es cierto lo afirmado por el Mincit, en ningún momento puede entenderse el hecho de publicar en Internet los textos o que estos sean de público conocimiento (aspecto discutible por cierto) como reemplazo de la publicación oficial. De esta manera, resulta incomprensible e inadmisible desde todo punto de vista que la autoridad encargada de la política comercial colombiana desconozca la obligación constitucional y legal de publicación oficial de las leyes de la República, aspecto que se erige como garantía institucional de conocimiento de las normas aprobadas para la sociedad en general.

Este caso se constituye como paradigma frente a la incorporación de diversos TLC al ordenamiento jurídico colombiano, ya que generó un precedente muy importante al ser el Memorando el primer asunto relacionado con un ALC que es declarado inexequible por el órgano competente de la Rama Judicial en Colombia.

\section{B. Sentencia C-1051/12 $2^{14}$}

De acuerdo con lo consignado en el expediente de la sentencia, los temas tratados en esta son:

Revisión constitucional del "Convenio Internacional para la Protección de Obtenciones Vegetales", del 2 de diciembre de 1961, revisado en Ginebra el 10 de noviembre de 1972, el 23 de noviembre de 1978 y el 19 de marzo de 1991 (Upov 91) y la Ley aprobatoria número 1518 del 13 de abril de 2012. ${ }^{15}$

\section{Hechos relevantes del caso}

El 4 de mayo del 2012, en uso de sus atribuciones establecidas en la CP, la Corte Constitucional con ponencia del entonces magistrado Juan Carlos Henao

14. Las normas invocadas o aplicadas en la sentencia son: Artículos 8, 79, 80, 95 numeral 8, 330, 1, 2, 150, 189, 241 numeral 10, 242 numeral 2, 278 numeral 5, 157, 158, 160, 165, 154, 163, 9, 226, 227 de la CP; Artículos 6, 16, 15 del Convenio 169 de la ort; Artículos 1 a 4 de la Decisión 345; Artículo 16 de la Decisión 391; Artículos 15, 20 y 26 de la Decisión 486; Artículo 76 de la Ley 99 de 1993; Ley 70 de 1993; Ley 21 de 1991; Artículos 32, 10 y 29 de la Declaración de las Naciones Unidas sobre los Derechos de los Pueblos Indígenas; Decreto 1397 de 1996; Artículo 21.2 de la Convención Americana sobre Derechos Humanos; Ley 1143 de 2007; Ley 243 de 1995; Decreto 533 de 1994; Artículo 7 del Decreto 2067 de 1991; Artículos 191, 169 a 173 de la Ley 5 de 1992.

15. Véase Corte Constitucional de Colombia. Sentencia C-1051/12. (M. P. Luis Guillermo Guerrero Pérez; Diciembre 5 de 2012).
Pére ${ }^{16}$ avocó el conocimiento del proceso de revisión constitucional.

El Ministerio de Ambiente y Desarrollo Sostenible (MADS) en su intervención manifiesta, entre otras consideraciones como la Ley 1518 de 2012, no cumplió el necesario agotamiento del derecho fundamental a la consulta previa con las comunidades indígenas y negras, y de esta manera solicita declarar su inexequibilidad.

La Corte Constitucional emitió la Sentencia C-1051 del 5 de diciembre de 2012, declarando inexequible la Ley 1518 del 13 de abril de 2012 aprobatoria de upov 91, considerando que la consulta previa a las comunidades étnicas se torna de obligatorio cumplimiento cuando la medida, sea legislativa o administrativa, afecte directa y específicamente a dichos pueblos en su autonomía, e impacte la preservación de su etnia y cultura.

\section{Observaciones}

Después de mucha espera (mayor a un año) la Sentencia C-1051/12 finalmente fue notificada el 31 de marzo de 2014, mediante edicto número 50 del 2014, una vez transcurridos un año, tres meses y veintiséis días después de su expedición. En este caso, el asunto refiere al siguiente problema jurídico: ¿es obligatoria la consulta previa para adoptar un instrumento internacional que busca proteger los derechos del obtentor de variedades vegetales?

La Unión Internacional para la Protección de las Obtenciones Vegetales (UPOV) es una organización intergubernamental con sede en Ginebra, cuya misión es proporcionar y fomentar un sistema eficaz para la protección de las variedades vegetales, con miras al desarrollo de nuevas variedades para beneficio de la sociedad. Colombia es miembro de dicha organización, al haber adherido al Convenio upov Acta del 78. ${ }^{17}$ La Ley 1518 del 2012 tiene como objeto adherir al Acta de 1991, con el fin de adoptar las modificaciones que dicha acta hace al Acta de 1978 (sin cambiar su esencia), y darle así un mejor desarrollo a este sistema de protección.

Las disposiciones de upov 91 nada tienen que ver con la integridad cultural y social, así como con la propiedad de las comunidades sobre sus territorios

\footnotetext{
16. Henao Pérez renunció el 28 de marzo del 2012, y en su reemplazo fue designado Luis Guillermo Guerrero Pérez.

17. Por virtud de la Ley 243 de 1995, declarada exequible mediante Sentencia C-262/96, Colombia adhirió al Acta de 1978, vigente en ese momento, pues para esa fecha no era posible adherirse al Acta de 1991 dado que esta sólo entró en vigor a partir de 1998.
} 
ancestrales. No se requería consultar a las minorías étnicas, como quiera que este instrumento internacional contiene estipulaciones de orden general dirigidas a proteger los derechos del obtentor de especies vegetales. El convenio UPOV 91 adopta un marco general de política pública dirigida a todos los colombianos que no afecta per se, o de manera directa, a las minorías étnicas.

$\mathrm{Al}$ respecto, y con el fin de reafirmar que no hay necesidad de consulta previa, es útil citar el aparte pertinente de la Sentencia C-750 de 2008, la cual declaró exequible la Ley 1143 de 2007, aprobatoria del APC con Estados Unidos, acuerdo que incorpora el compromiso de Colombia de adherirse al Convenio de la upov en su Acta del 91:

Sin embargo, también ha considerado esta corporación, que tratándose específicamente de medidas legislativas, es claro que el deber de consulta no surge frente a toda medida legislativa que sea susceptible de afectar a las comunidades indígenas, sino únicamente frente a aquellas que puedan afectarlas directamente, evento en el cual, a la luz de lo expresado por la Corte en la Sentencia C-169 de 2001, la consulta contemplada en el artículo 6 del Convenio 169 de la oIt deberá surtirse en los términos previstos en la Constitución y en la ley.

En el presente caso, no se requería adelantar la consulta previa del Acuerdo a las comunidades indíge- nas y tribales, por cuanto las normas del Capítulo Dieciocho sobre medio ambiente, así como todas las del Acuerdo, han sido expedidas de manera uniforme para la generalidad de los colombianos, y no contienen disposiciones que afecten a éstos grupos de manera específica y directa en su calidad de tales; es decir, ninguna de ellas les impone restricciones o gravámenes o les confiere beneficios a éstos grupos étnicos. ${ }^{18}$

En conclusión, es claro que en el presente caso no se requería consulta previa y la Corte Constitucional se equivocó en declarar inexequible la Ley 1518 de 2012, al dejarse confundir por la infortunada intervención del MADS.

\section{LEY DE IMPLEMENTACIÓN DEL TLC CON Estados Unidos}

Especial atención merece la expedición de la Ley 1520 del 13 de abril de 2012, conocida como la Ley de Implementación del TLC con Estados Unidos. A menos de una semana de nacer a la vida jurídica recibió su primera demanda de inconstitucionalidad (17 de abril), y en total fue demandada en seis oportunidades. Los argumentos de las acciones se resumen en la tabla 3 .

Tabla 3. Demandas de inconstitucionalidad contra la Ley de Implementación del tLC con Estados Unidos

\begin{tabular}{|c|c|c|c|}
\hline Actor & nente & Cargos & Trámite \\
\hline 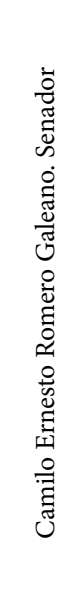 & 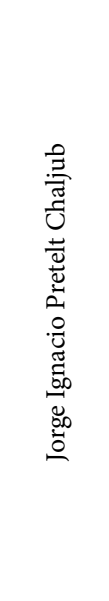 & $\begin{array}{l}\text { Vicios de fondo: } \\
\text { Artículo 2: Acorde con la definición de lucro cualquier uso o disfrute de una obra, } \\
\text { así no sea económico, se considerará delito. La definición de fijación no especifica el } \\
\text { tiempo necesario para que sea estable y permanente. } \\
\text { Artículo 3: Viola el debido proceso porque presume al demandante como autor. } \\
\text { Artículo 13: Penaliza al usuario que enlace cualquier programa de televisión para } \\
\text { ser publicado en un blog o una web violando la libertad de expresión en medios } \\
\text { masivos, así como el derecho a la información porque no pondera los derechos de } \\
\text { autos y los fundamentales. } \\
\text { Artículo 14: Vulnera el derecho al acceso de información porque penaliza la copia } \\
\text { privada. } \\
\text { Artículo 15: Vulnera el derecho a la igualdad, la libertad de expresión y el acceso a la } \\
\text { información, al no contemplar excepciones al derecho de autor. } \\
\text { Artículos } 16 \text { y 17: Desconoce la libertad de expresión, el derecho a la información y el } \\
\text { conocimiento, al sancionar sin respetar el uso justo y excepciones al derecho de autor. }\end{array}$ & $\begin{array}{l}\text { Radicado (17/4/2012). } \\
\text { Asignado a ponente } \\
(18 / 4 / 2012) \text {. } \\
\text { Notificación auto que } \\
\text { admite demanda contra } \\
\text { artículos } 2,3,15 \text { al } 17 \text { y } 19 \\
\text { e inadmite contra artículos } \\
13,14 \text { y } 21 \text { (2/5/2012). } \\
\text { Notificación auto que } \\
\text { rechaza demanda contra } \\
\text { artículos } 13,14 \text { y } 21 \text { y con- } \\
\text { cede súplica (28/5/2012). } \\
\text { Plazo }(31 / 5 / 2012) \text {. } \\
\text { Súplica presentada por el } \\
\text { actor }(31 / 5 / 2012) \text {. }\end{array}$ \\
\hline
\end{tabular}


Cont.

\begin{tabular}{|c|c|c|c|}
\hline & & $\begin{array}{l}\text { Artículo 19: Vulnera el derecho a la intimidad al facultar a las autoridades el acceso } \\
\text { a los datos personales del supuesto infractor. } \\
\text { Artículo 21: Vulnera la unidad de materia al regular la Ley } 182 \text { de } 1995 \text { sobre televi- } \\
\text { sión, porque este artículo no está sustentado en la exposición de motivos, no tiene } \\
\text { relación con los derechos de autor, el TLC ni sus compromisos. } \\
\text { Vicios de trámite: } \\
\text { El Congreso acordó la votación nominal pero se hizo en bloque, lo cual viola el } \\
\text { artículo } 160 \text { de la Constitución. } \\
\text { La ley debió tramitarse en la comisión primera y no en la segunda porque se trataba } \\
\text { de temas de propiedad intelectual. } \\
\text { súpLIcA } \\
\text { 1. Artículo 13: Se privilegia el derecho de autor de una obra generado por razones de } \\
\text { lucro (no fundamental) sobre el derecho del colectivo de ciudadanos a ser informa- } \\
\text { dos e informar a otros utilizando como medio un bien público (Internet). } \\
\text { 2. Artículo 14, literal a: Quien accede a un bien público (Internet) y lo usa para la } \\
\text { difusión de su pensamiento puede incurrir en sanción civil, resultando despropor- } \\
\text { cionada la protección del autor. } \\
\text { 3. Artículo 21: No hay unidad de materia debido a que el objetivo no es acorde con } \\
\text { las obligaciones de implementación de compromisos con el tLc. No sustentado en } \\
\text { exposición de motivos, no conexidad con la temática de la ley (derechos de autor). } \\
\text { Las cuotas de pantalla en Tv no son temas de conexidad con derechos de autor. }\end{array}$ & $\begin{array}{l}\text { Recurso asignado a Hum- } \\
\text { berto Antonio Sierra Porto } \\
(1 / 6 / 2012) \text {. } \\
\text { Notificación auto que } \\
\text { confirma rechazo demanda } \\
\text { contra artículos } 13,14 \text { y } 21 \\
(8 / 8 / 2012) \text {. } \\
\text { Fijación en lista (16 al } \\
\text { 30/8/2012) } \\
\text { Intervención MincIT } \\
\text { (28/8/2012) } \\
\text { Concepto PGN }(21 / 9 / 2012) \\
\text { Sentencia }(13 / 2 / 2013)\end{array}$ \\
\hline 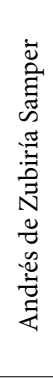 & 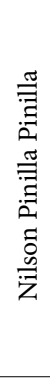 & $\begin{array}{l}\text { Vulneración del artículo } 160 \text { de la Constitución: } \\
\text { Entre el primer y el segundo debate, pasaron sólo cuatro días y no ocho como } \\
\text { establece la norma. } \\
\text { No dejaron pasar los } 15 \text { días entre aprobación en una cámara y el inicio del debate } \\
\text { en la otra. }\end{array}$ & $\begin{array}{l}\text { Radicado (18/4/2012). } \\
\text { Asignado a ponente } \\
(2 / 5 / 2012) \text {. } \\
\text { Notificación auto que inad- } \\
\text { mite demanda }(22 / 5 / 2012) \text {. } \\
\text { Notificación auto que } \\
\text { rechaza demanda y con- } \\
\text { cede súplica }(6 / 6 / 2012) \text {. } \\
\text { Archivo }(13 / 6 / 2012) \text {. }\end{array}$ \\
\hline 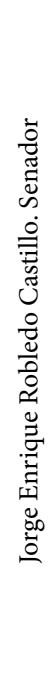 & 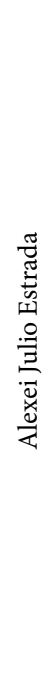 & $\begin{array}{l}\text { Artículos } 142 \text { y 157: La ley no surtió debate en las comisiones constitucionales per- } \\
\text { manentes del Congreso competentes porque es una norma sobre derechos de autor y } \\
\text { sólo el artículo } 1 \text { señala la implementación del TLC. } \\
\text { Artículo 153: Los derechos de autor son fundamentales por lo que debía cumplir } \\
\text { procedimiento de ley estatutaria y no fue tramitada como tal. } \\
\text { Violación de los derechos a la libertad de expresión y acceso a la información: } \\
\text { Adicionar } 20 \text { años a la protección de los derechos de autor restringe de manera } \\
\text { irracional el derecho de los ciudadanos a acceder libremente a la información de las } \\
\text { obras protegidas. } \\
\text { La prohibición de retransmitir señales de televisión por Internet es excesiva, la } \\
\text { transmisión por televisión ya obtenía cuantiosas utilidades. } \\
\text { La ley va más allá del Acuerdo ADPIC de la omC y de las obligaciones del TLC, e } \\
\text { incluso es más restrictiva que la de EE.UU. porque no permite las limitaciones y } \\
\text { excepciones generales. } \\
\text { Aumentar la protección de propiedad intelectual evita que la información llegue } \\
\text { a más capas sociales y en consecuencia crecerá a quienes se ven excluidos de los } \\
\text { avances de la humanidad. }\end{array}$ & $\begin{array}{l}\text { Radicado (4/5/2012). } \\
\text { Asignado a ponente } \\
(16 / 5 / 2012) \text {. } \\
\text { Notificación auto } \\
\text { que admite demanda } \\
\text { (5/6/2012). } \\
\text { Fijación en lista (26/7 al } \\
\text { 9/8/2012) } \\
\text { Intervención MincIT } \\
\text { (9/8/2012) } \\
\text { Concepto PGN (5/9/2012) } \\
\text { Sentencia }(23 / 1 / 2013)\end{array}$ \\
\hline
\end{tabular}


Cont.

\begin{tabular}{|c|c|c|c|}
\hline 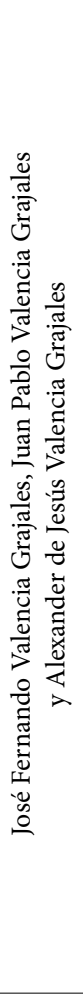 & 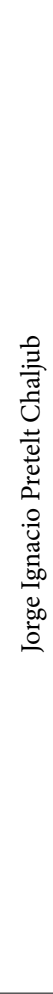 & $\begin{array}{l}\text { Parte formal: } \\
\text { El Congreso acordó la votación nominal pero se hizo en bloque, no se respetaron } \\
\text { los tiempos mínimos y no se cumplieron los trámites legislativos tales como la } \\
\text { publicación en el Diario Oficial de los cuatro debates, lo cual viola el artículo } 160 \text { de } \\
\text { la Constitución. } \\
\text { La ley debió tramitarse en la comisión primera y no en la segunda porque se trataba } \\
\text { de temas de propiedad intelectual. } \\
\text { Se violó la unidad de materia del artículo } 158 \text { constitucional al regular un nuevo tipo } \\
\text { penal en blanco, y el artículo } 21 \text { no está sustentado en la exposición de motivos, no } \\
\text { tiene relación con los derechos de autor, el TLC ni sus compromisos. } \\
\text { Parte de fondo: } \\
\text { Al presentarse sólo dos debates de los cuatro necesarios se incumplió el artículo } 149 \\
\text { constitucional. } \\
\text { Normas inconstitucionales: } \\
\text { Artículo 1: La norma no se ve desarrollada en el articulado. } \\
\text { Artículo 2: Cualquier uso o disfrute de una obra -así no sea económico- se consi- } \\
\text { derará delito, lo que resulta desproporcional porque protege un derecho individual } \\
\text { vulnerando un derecho colectivo. La fijación criminaliza al usuario de la informa- } \\
\text { ción al penalizar el uso y la guarda de imágenes; por ejemplo, en la memoria caché o } \\
\text { las páginas web acción natural al uso del computador y al acceso de la información. } \\
\text { Artículo 3: Viola el debido proceso porque presume al demandante como autor. } \\
\text { Artículo 13: Penaliza al usuario que enlace cualquier programa de televisión para } \\
\text { ser publicado en un blog o una web violando la libertad de expresión en medios } \\
\text { masivos, así como el derecho a la información porque no pondera los derechos de } \\
\text { autos y los fundamentales. }\end{array}$ & $\begin{array}{l}\text { Radicado }(25 / 5 / 2012) \text {. } \\
\text { Asignado a ponente } \\
(30 / 5 / 2012) \text {. } \\
\text { Notificación auto que } \\
\text { admite demanda e inad- } \\
\text { mite un cargo (6/7/2012). } \\
\text { Notificación auto } \\
\text { que rechaza un cargo } \\
\text { (24/7/2012). } \\
\text { Fijación en lista (7/9 al } \\
\text { 20/9/2012) } \\
\text { Intervención MincIT } \\
\text { (20/9/2012) } \\
\text { Concepto PGN } \\
\text { (18/10/2012) } \\
\text { Sentencia (6/3/2013) }\end{array}$ \\
\hline 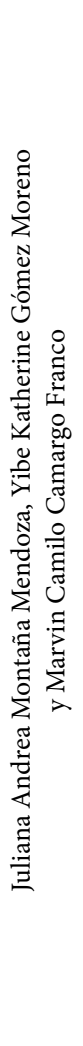 & 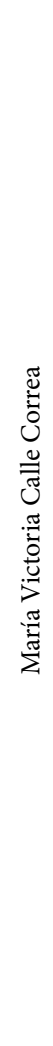 & $\begin{array}{l}\text { Violación del artículo } 152 \mathrm{CP} \text { al regular derechos fundamentales sin ley estatutaria. } \\
\text { Afectación de derechos fundamentales a la igualdad, la información, el debido pro- } \\
\text { ceso, la educación y la cultura, al restringir hasta el punto de evitar que la sociedad } \\
\text { acceda al conocimiento. } \\
\text { Transgresión del artículo } 67 \mathrm{CP} \text { (derecho a la educación) al negar la posibilidad de } \\
\text { acceder al conocimiento restringiendo los sitios web. } \\
\text { Artículo } 13 \text { Ley } 1520 \text { : } \\
\text { Violación artículo } 13 \text { CP sobre la igualdad ante la ley al intentar restringir el acceso } \\
\text { gratuito a la información. } \\
\text { Violación artículo } 20 \text { CP al afectar las libertades de expresión, opinión e información. } \\
\text { Artículo } 14 \text { Ley } 1520: \\
\text { Vulneración artículo } 29 \text { CP sobre debido proceso al presumir la culpabilidad e impo- } \\
\text { ner a la persona la carga de demostrar su inocencia. } \\
\text { Derecho a la cultura: } \\
\text { Se afecta la cultura que fundamenta la nacionalidad y actividad de la sociedad en su } \\
\text { conjunto, como proceso individual y colectivo para crear identidad. } \\
\text { Uno de los fines esenciales del Estado es facilitar la participación de todos en la vida } \\
\text { cultural de la nación (artículo } 2 \text { cP). } \\
\text { Es obligación del Estado reconocer y proteger la diversidad étnica y cultural de la } \\
\text { nación (artículo } 7 \text { cP). } \\
\text { Entre los derechos de los niños está el derecho a la cultura (artículo } 44 \text { cP). } \\
\text { El artículo } 70 \text { CP prescribe el deber del Estado de promover y fomentar el acceso a la } \\
\text { cultura de todos los colombianos en igualdad de oportunidades. } \\
\text { El artículo } 71 \text { cP contempla el deber estatal de incluir en los planes de desarrollo } \\
\text { medidas para el fomento de la cultura. }\end{array}$ & $\begin{array}{l}\text { Radicado (1/6/2012). } \\
\text { Asignado a ponente } \\
(21 / 6 / 2012) \text {. } \\
\text { Notificación auto que } \\
\text { admite demanda e inad- } \\
\text { mite un cargo (11/7/2012). } \\
\text { Fijación en lista (19/7 al } \\
\text { 2/8/2012) } \\
\text { Concepto PGN }(22 / 8 / 2012) \\
\text { Sentencia }(18 / 2 / 2013)\end{array}$ \\
\hline
\end{tabular}


Cont.

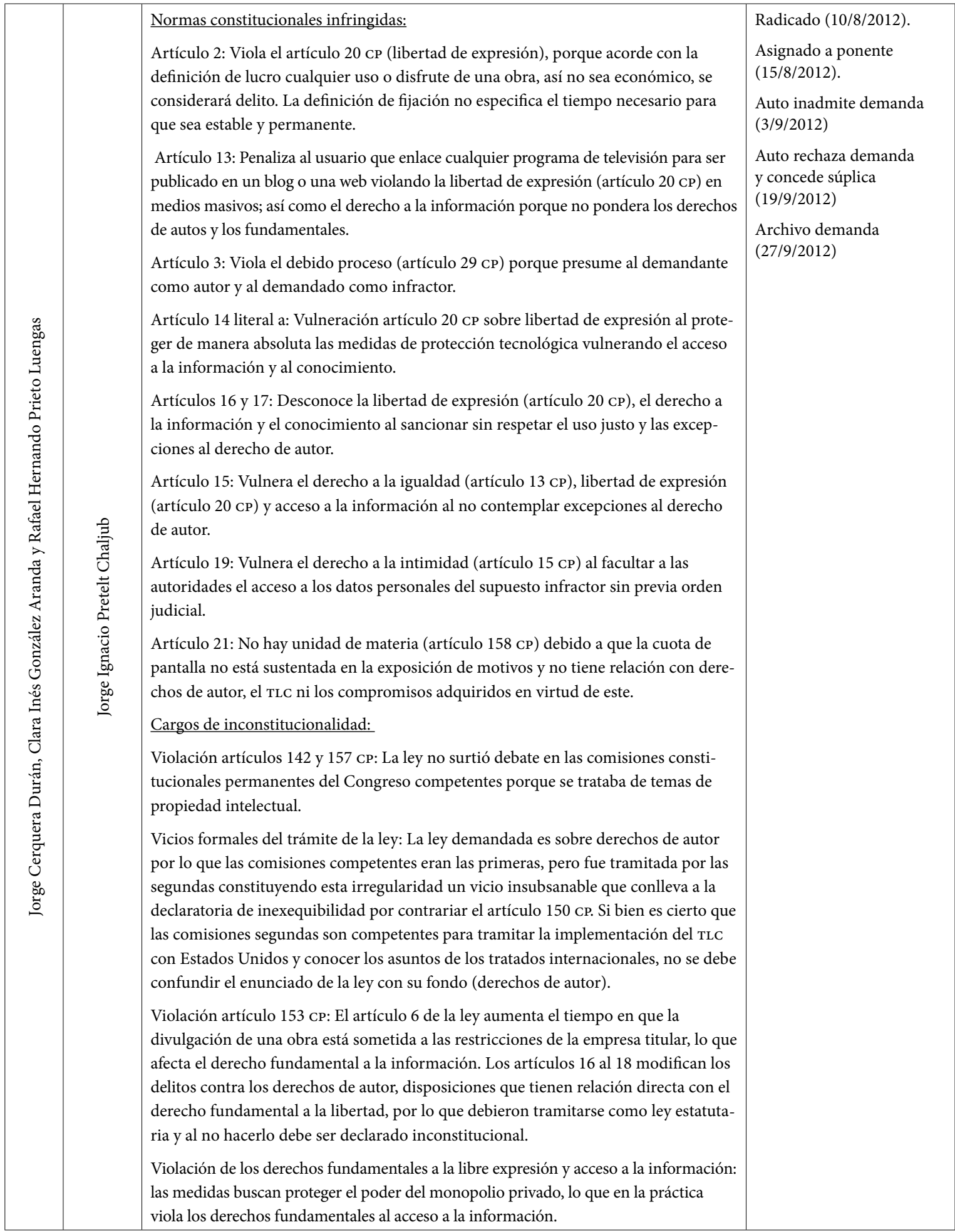

Fuente: elaboración propia 
De las seis acciones de inconstitucionalidad contra la Ley 1520 de 2012, dos fueron archivadas, cuatro llegaron a sentencia declarando la inexequibilidad (siendo la primera la Sentencia C-011 de 2013), y las otras tres declararon estarse a lo resuelto respecto a la primera sentencia. Por lo tanto, sólo se analizará dicha providencia.

Así, la Corte Constitucional debió aplicar el principio de economía procesal y, ya que todas las demandas atacaban la misma norma, procedía entonces a acumular los expedientes y emitir una sola sentencia.

\section{A. Sentencia C-011 de $2013^{19}$}

De acuerdo con lo consignado en el expediente de la sentencia, el tema tratado en esta es:

Demanda de inconstitucionalidad contra la Ley 1520 de 2012 "por medio de la cual se implementan compromisos adquiridos por virtud del Acuerdo de Promoción Comercial suscrito entre la República de Colombia y los Estados Unidos de América y su Protocolo Modificatorio, en el marco de la política de comercio exterior e integración económica”. ${ }^{20}$

\section{Hechos relevantes del caso}

El senador Jorge Enrique Robledo Castillo presentó acción pública de inconstitucionalidad contra la Ley 1520 de 2012, solicitando que se declare su inexequibilidad por violación de los artículos 142 y 157 de la CP. Esto en razón a que no surtió debate en las comisiones constitucionales permanentes del Congreso competentes, e infringió el artículo 153 de la CP al no tramitarse la ley como estatutaria, ya que al regular el derecho de autor se afectan derechos fundamentales. El 1 de junio de 2012 la Corte Constitucional, con ponencia del entonces magistrado Humberto Antonio Sierra Porto, ${ }^{21}$ admite la demanda.

19. Las normas invocadas o aplicadas en la sentencia son: Artículos 241, 19 al 21, 142, 157, 13, 15 al 17, 29, 67, 44, 152, 153, 158, 242 numeral 2 y 278 numeral 5 de la CP; Artículo 2 de la Ley 3 de 1992; Artículos 32, 178, 8, 11, 12, 27, 29, 165, 58 al 71 y 247 de la Ley 23 de 1982; Artículo 30.3 de la Convención sobre los Derechos de las Personas con Discapacidad; Ley 1143 de 2007; Artículo 39 de la Decisión 351 de 1993; Ley 166 de 2007; Artículos 2 y 3 de la Ley 1032 de 2006; Artículo 1 de la Ley 754 de 2002; Artículo 146 de la Ley 5 de 1992 y Ley 719 de 2001

20. Véase Corte Constitucional de Colombia. Sentencia C-011/2013. (M. P. Alexei Julio Estrada; Enero 23 de 2013).

21. A Sierra Porto se le venció su período el 1 de septiembre de 2012, y en su reemplazo fue encargado Alexei Julio Estrada.
El Mincit presentó en término la defensa de constitucionalidad, argumentando que la finalidad de la Ley de Implementación es el desarrollo de los compromisos adquiridos en virtud del APC con Estados Unidos y, de conformidad con lo establecido en la Ley $3^{\text {a }}$ de 1992, la Comisión Segunda es competente para conocer proyectos de ley sobre tratados públicos, comercio exterior, integración económica y zonas de libre comercio. Asimismo, la ley demandada no necesitaba tramitarse como estatutaria porque no reguló derechos morales de autor que puedan ser considerados fundamentales.

La Corte Constitucional emitió la Sentencia C-011 del 23 de enero de 2013, declarando inexequible la Ley 1520 del 13 de abril de 2012, por medio de la cual se implementan compromisos del APC con Estados Unidos, considerando que la ley inició su trámite en el Congreso en una comisión que no era competente para ello.

La Ley de Implementación regulaba tres asuntos: derechos de autor, propiedad industrial y cuota de pantalla. Para no tener inconvenientes de constitucionalidad hacia futuro en materia formal, se decidió dividir la ley en sus tres temas. Lo relativo a propiedad industrial se aprobó mediante Ley 1648 de 2013; el tema de cuota de pantalla está en trámite legislativo y lo referente a derechos de autor no ha sido presentado ante el Congreso.

\section{Observaciones}

Es importante profundizar el análisis de la Sentencia C-011/13, la cual declaró inexequible la Ley 1520 de 2012 al no tramitarse en la Comisión del Congreso competente.

En la sentencia estudiada, el tema se circunscribe al siguiente problema jurídico: ¿puede una Comisión del Congreso asumir la competencia de un proyecto de ley que pudiera abordar materias que eventualmente corresponderían a dos o más comisiones?

Eventualmente, la temática de un proyecto de ley puede involucrar más de una comisión del Congreso. En este caso, el proyecto de ley cubre materias como derechos de autor (Comisión Primera), marcas (Comisión Cuarta) y regulación del contenido de televisión, la cual corresponde a un asunto propio del comercio transfronterizo de servicios.

Sobre este particular, la Corte ha señalado:

En muchas ocasiones la distribución de los proyectos de ley para su aprobación en primer debate es aproximada, debido a las condiciones especiales del 
contenido de cada proyecto. Si bien la Ley 3 de 1992 hace una distribución temática entre las comisiones permanentes, la amplitud y variedad de los principios constitucionales que deben ser desarrollados por ley y la dinámica y especificidad de cada materia exigen cierta flexibilidad al momento de distribuir los proyectos de ley para su estudio, trámite y aprobación en primer debate. $^{22}$

La flexibilidad significa que el juez constitucional no puede demandar precisión matemática al presidente de la Cámara en la asignación de los proyectos de ley a las comisiones legislativas. El juicio de constitucionalidad exige que la Corte Constitucional constate un mínimo de razonabilidad en la asignación del proyecto a la comisión respectiva en el marco de las competencias temáticas asignadas por el legislador, pero también debe tener en cuenta las diferencias de criterio que pudieran surgir con la definición de tal asignación.

Si la decisión del presidente de la Cámara de repartir un proyecto de ley a una comisión guarda un mínimo de razonabilidad respecto a los asuntos de competencia de las comisiones, la Corte Constitucional debe salvaguardar la decisión en consideración a la aplicación del principio de flexibilidad de interpretación de la norma.

La Corte Constitucional ha precisado que el número de artículos referidos a un mismo tema no impone, necesariamente, el criterio dominante o la finalidad del proyecto, por lo que el factor matemático no es, por sí solo, una pauta justificada de asignación. En consecuencia, pese a que el proyecto tenga una cantidad importante de normas relacionadas con un asunto en particular, la decisión de los presidentes de las cámaras puede adoptar un criterio de asignación que dé prioridad a la finalidad del proyecto. Así, en la citada sentencia, la Corte Constitucional se pronunció en los siguientes términos:

Cuando el debate de constitucionalidad versa sobre la competencia o incompetencia de una comisión permanente para tramitar un proyecto de ley, es indispensable señalar cuál debe ser el criterio dominante que debe aplicar el Presidente de la respectiva Cámara para remitir el proyecto a la comisión competente [...] al identificar la naturaleza material de un proyecto de ley para remitirlo a la comisión permanente, si se genera duda ésta debe resolverse a partir de la finalidad de la ley y no con base en

22. Véase Corte Constitucional de Colombia. Sentencia C-540 de 2001. (M. P. Jaime Córdoba Triviño; Mayo 22 de 2001). un criterio cuantitativo o matemático. No será necesariamente el mayor número de artículos que se refieran a un mismo tema dentro del proyecto el que se constituya en el criterio prevalente para tomar la decisión, pues pueden darse casos en que la esencia temática del proyecto se extracte de algunos de sus artículos solamente. $^{23}$

Dado que el objetivo de la Ley de Implementación es la incorporación de compromisos internacionales en materia comercial, el proyecto de ley se encomendó a la Comisión Segunda, encargada de tramitar los asuntos propios del comercio internacional y de la integración económica, ya que era esa la finalidad del proyecto de ley.

En conclusión, la Ley 1520 de 2012 debió haber sido declarada exequible tanto en su aspecto formal como material, ${ }^{24}$ y la Corte Constitucional desconoció los criterios de flexibilidad, razonabilidad y finalidad en la asignación de competencia legislativa.

\section{Tratado de Budapest}

A. Sentencia $C-350^{25}$

De acuerdo con lo consignado en el expediente de la sentencia, el tema tratado en esta es:

Revisión constitucional del "Tratado de Budapest sobre el reconocimiento internacional del depósito de microrganismos a los fines del procedimiento en materia de patentes", adoptado en Budapest, el 28 de abril de 1977 y enmendado el 26 de septiembre de 1980 y su "Reglamento", adoptado el 28 de abril de 1977 y modificado el 20 de enero de 1981 y el 1 de octubre de 2002 y la Ley 1515 de febrero 6 de 2012, aprobatoria del mismo. ${ }^{26}$

23. Véase Corte Constitucional de Colombia, supra, nota 20

24 . En cuanto al aspecto sustancial, el juez constitucional se abstuvo de pronunciarse.

25. Las normas invocadas o aplicadas en la sentencia son: Artículos 226, 227, 241 numeral 10, 160, 9, 150 numerales 16 y 24, 189, 61, 8, 58 inciso 2, 81 y 330 de la CP; Artículos 7 al 11 y 15 de la CV; Ley 565 de 2000; Ley 545 de 1999; Ley 463 de 1998; Artículos 568 al 570 y 597 del Código de Comercio (C. Co.); Artículos 14 y 29 de la Decisión 486 de 2000 y Decisión 689 de 2008.

26. Véase Corte Constitucional de Colombia. Sentencia C-350 DE 2013. (M. P. Mauricio González Cuervo; Junio 19 de 2013). 


\section{Hechos relevantes del caso}

El 2 de marzo del 2012, en uso de sus atribuciones establecidas en la CP, la Corte Constitucional con ponencia del magistrado Mauricio González Cuervo avocó el conocimiento del proceso de revisión constitucional.

La Corte Constitucional emitió la Sentencia C-350 del 19 de junio de 2013, declarando exequible la Ley 1515 de 2012, pero consideró que las estipulaciones de alcance del reconocimiento del depósito internacional de microorganismos del literal a del artículo 3.1, y la no restricción a la exportación e importación de ciertos tipos de microorganismos del artículo 5 del tratado serán exequibles, siempre que el acceso al material biológico objeto de depósito regulado en el presente tratado, su salida del país y el reconocimiento de la respectiva patente, se efectúen de conformidad con el régimen constitucional colombiano, específicamente con lo prescrito por la CP en los siguientes artículos:

- Artículo 8. Protección de riquezas culturales y naturales.

- Artículo 58, inciso segundo. Función ecológica de la propiedad.

- Artículo 81. Regular el ingreso y la salida del país de los recursos genéticos y su utilización de acuerdo con el interés nacional.

- Artículo 330. Confiere a las autoridades de los pueblos indígenas la función de velar por la conservación de los recursos naturales de su territorio.

En consecuencia, establece una condición consistente en que para realizar el depósito del instrumento de adhesión al tratado, se debe hacer la siguiente declaración interpretativa:

El acceso al material biológico objeto de depósito regulado en el presente Tratado, su salida del país y el reconocimiento de la respectiva patente deberán realizarse de conformidad con las protecciones previstas en el régimen constitucional colombiano, específicamente, en los artículos 8,58 , inciso segundo, 81 , inciso segundo y 330 de la Constitución Política. ${ }^{27}$

\section{Observaciones}

En la sentencia, el tema se circunscribe al siguiente problema jurídico: ¿las disposiciones del Tratado de Budapest observan la $\mathrm{CP}$ ?
El tratado no modifica ni crea la obligación de depósito de microorganismos en Colombia, pues está prevista en la Decisión Andina 486. Lo que se pretende es estandarizar, simplificar y agilizar los trámites respectivos, al permitir que los depósitos sean efectuados ante una autoridad internacional de depósito, la cual cuente con capacidad técnica para recibir y conservar microorganismos, con independencia de que dicha autoridad se encuentre dentro o fuera del territorio colombiano.

En efecto, la Decisión Andina 486 de 2000 establece lo siguiente:

Artículo 29. [...]Serán válidos los depósitos efectuados ante una autoridad internacional reconocida conforme al Tratado de Budapest sobre el Reconocimiento Internacional del Depósito de Microorganismos a los Fines del Procedimiento en Materia de Patentes, de 1977, o ante otra institución reconocida por la oficina nacional competente para estos efectos. ${ }^{28}$

De esta forma, el derecho comunitario andino que es supranacional y debe ser aplicado de manera directa y con efecto inmediato ya contemplaba tal obligación, la cual hacía parte del ordenamiento jurídico colombiano.

Asimismo, el tratado regula en qué casos puntuales puede requerirse un nuevo depósito, su procedimiento y sus efectos, y dispone que no se deben aplicar restricciones a las importaciones y exportaciones de los microorganismos que están depositados o destinados a ser depositados en virtud del tratado, salvo que la restricción sea necesaria en consideración a la seguridad nacional o a riesgos para la salud o el medio ambiente.

El Tratado de Budapest regula de forma especial la forma de divulgación del contenido de solicitudes de patente sobre microorganismos y material biológico mediante su depósito, con el principal objetivo de evitar que se realicen tantos depósitos como países donde se solicite una patente.

Al tener como finalidad primordial hacer más eficientes, ágiles y efectivos los trámites y procedimientos para obtener el registro de una patente cuando en ella se encuentren involucrados microorganismos u otro material biológico, este tratado genera beneficios para los solicitantes y titulares de patentes nacionales y extranjeros, y por lo tanto, impulsará los fines ideológicos y la razón de ser del

28. Véase Decisión 486 de 2000. [Comunidad Andina]. Que establece el Régimen Común sobre Propiedad Industrial. Septiembre 14 de 2000 . 
sistema de propiedad industrial, esto es, promover y proteger la innovación, la investigación y el desarrollo. En este caso, los beneficios se reflejarán directamente en el campo científico.

En conclusión, la declaración interpretativa ordenada es una manifestación de ese reiterado y polémico estilo de modular los fallos por parte de la Corte Constitucional, al dar interpretaciones que se convierten en verdaderas regulaciones e implica en la realidad formular reservas al tratado internacional.

\section{ACUERDo MARCO DE LA AP}

\section{A. Sentencia C-258 del $2014^{29}$}

De acuerdo con lo consignado en el expediente de la sentencia, el tema tratado en esta es:

Revisión constitucional de la Ley 1628 del 22 de mayo de 2013, "por medio de la cual se aprueba el 'Acuerdo marco de la Alianza del Pacífico' entre la República de Colombia, la República de Chile, los Estados Unidos Mexicanos y la República del Perú, firmado en la ciudad de Antofagasta, Chile, el seis de junio de 2012".30

\section{Hechos relevantes del caso}

El 21 de junio del 2013 en uso de sus atribuciones establecidas en la CP, la Corte Constitucional con ponencia de la magistrada María Victoria Calle Correa avocó el conocimiento del proceso de revisión constitucional.

Posterior a la defensa de constitucionalidad presentada en término por el Mincit, un ciudadano - quien había sido asesor del Despacho del Ministro en el Ministerio de Agricultura y Desarrollo Rural (MADR) - en su intervención extemporánea ${ }^{31}$

29. Las normas invocadas o aplicadas en la sentencia son: Artículos 241, Preámbulo, 9, 227, 189, 150, 224, 154, 157 a 169, 145, 146, 227, 226, 2, 336, 1, 4, 240, 242 numeral 2, 278 numeral 5, 64 a 66 de la CP; Artículo 7 de la cv; Artículos 156, 191, 169 a 173 y 202 de la Ley 5 de 1992; Decreto 2067 de 1991; Decreto 573 de 2012; Ley 3 de 1992 y Ley 754 de 2002.

30. Véase Corte Constitucional de Colombia. Sentencia C-258 DE 2014. (M. P. María Victoria Calle Correa; Abril 23 de 2014).

31. El plazo de fijación en lista fue del 9 al 23 de octubre de 2013; la intervención descrita fue radicada el 6 de noviembre del mismo año y presentada nuevamente el 20 de enero de 2014. le informa a la Corte Constitucional que falta la última página del tratado en las publicaciones de las fuentes públicas conocidas, omisión que puede generar errores en la aprobación de la ley, y por lo tanto, solicita declarar su inexequibilidad.

El 21 de enero del 2014, la Secretaria Jurídica de la Presidencia de la República (SJPR) presentó un escrito donde argumenta principalmente:

- Posterior al trámite de sanción presidencial el Gobierno Nacional advirtió que en razón a un error secretarial en el Congreso, al transcribir el texto del acuerdo sometido a aprobación se omitió incluir la última página del tratado, error que permaneció en todo el trámite.

- Tanto en la Gaceta del Congreso 625 de 2012 como en las Gacetas 205, 250 y 251 de 2013, figura constancia del Grupo de Tratados del Ministerio de Relaciones Exteriores (MRE), en la cual establece que el texto presentado por el Gobierno Nacional es copia fiel y completa ( 9 folios) del texto en español del instrumento internacional que reposa en su archivo.

La Corte Constitucional consideró que no es posible subsanar el vicio de falta de publicación de la última página del tratado que se presentó a lo largo del trámite legislativo, dado que tendría que hacerlo en 30 días y en tal plazo no se puede rehacer todo el trámite. En consecuencia, emitió la sentencia C-258 del 23 de abril de 2014 en la que declara inexequible la Ley 1628 del 22 de mayo de 2013.

De esta forma, el Acuerdo Marco de la AP tuvo que repetir trámite de incorporación al Derecho interno, en el cual fue aprobado por la Ley 1721 de 2014 y declarado exequible junto con su ley aprobatoria por la Corte Constitucional mediante sentencia C-63 del 15 de abril de 2015.

\section{Observaciones}

A este caso, se aplican en esencia las mismas observaciones expresadas para el asunto del "Memorando de Entendimiento con los Estados AELC", razón por la cual no se justifica repetirlas. Adicionalmente, es preocupante lo manifestado por la SJPR en el sentido de que pese a la constancia del MrE de haber entregado copia integral del texto del tratado a la Rama Legislativa, las publicaciones oficiales del Congreso sobre el Acuerdo Marco de la AP estén incompletas. Esta situación descrita podría generar desconfianza respecto a la actividad desplegada en el interior del Parlamento colombiano. 


\section{ConCLUSIONES}

La creciente entrada en vigor de acuerdos comerciales por parte de Colombia genera una alta responsabilidad en el sentido de honrar las obligaciones internacionales que de ellos se derivan. Ahora bien, la política comercial de Colombia ha tendido puentes para el aprovechamiento de grandes oportunidades para el sector exportador colombiano. En el proceso de incorporación de los tratados internacionales al Derecho interno colombiano, intervienen todas las ramas del poder público, lo que garantiza un adecuado balance institucional. En la revisión constitucional de tratados internacionales y normas de implementación, la Corte Constitucional, en ocasiones, ha tomado distancia de la regulación emitida por el Gobierno Nacional, lo cual genera verdaderas vicisitudes para el cabal cumplimiento de los compromisos comerciales internacionales de Colombia.

La publicación oficial e integral del texto de la ley son requisitos que desarrollan los principios de publicidad y transparencia, necesarios en la producción normativa en un Estado Social de Derecho a fin de garantizar el adecuado conocimiento de las normas, tanto por parte del regulador, como de la sociedad a la cual están destinadas. Por tanto, la Corte Constitucional debe procurar notificar sus sentencias oportunamente, y así evitar la inseguridad jurídica tanto en el Derecho interno colombiano, como en el Derecho internacional.

En el análisis de constitucionalidad de una ley se debe aplicar el principio de economía procesal, así como respetar los criterios de flexibilidad, razonabilidad y finalidad en la asignación de competencia legislativa. Tratándose de tratados internacionales, el juez constitucional debería determinar siempre si una norma es exequible o no, y de esta manera evitar modular los fallos, lo cual genera confusión e inseguridad jurídica. La revisión constitucional de tratados internaciones y las normas que los implementan contribuye con la paz en la resolución de posibles controversias, especialmente a nivel interno.

\section{REFERENCIAS}

Consejo Superior de Comercio Exterior. Agenda de NegoCiaciones Comerciales de Colombia. (2011).

Concepto 4999 de 2010. [Procuraduría General de la Nación]. Agosto 2 de 2010.

Constitución Política de Colombia. Artículo 278, numeral 5.

Corte Constitucional de Colombia. Sentencia C-750/2008 (M. P. Clara Inés Vargas Hernández; Julio 24 de 2008).

Corte Constitucional de Colombia. Sentencia C-941-10. (M. P. Jorge Iván Palacio Palacio; Noviembre 24 de 2010).

Corte Constitucional de Colombia. Sentencia C-1051/12. (M. P. Luis Guillermo Guerrero Pérez; Diciembre 5 de 2012).

Corte Constitucional de Colombia. Sentencia C-011/2013 (M. P. Alexei Julio Estrada; Enero 23 del 2013).

Corte Constitucional de Colombia. Sentencia C-350 DE 2013. (M. P. Mauricio González Cuervo; Junio 19 de 2013).

Corte Constitucional de Colombia. Sentencia C-258 DE 2014. (M. P. María Victoria Calle Correa; Abril 23 de 2014).

Eric Tremolada. El Acuerdo Comercial con la Unión Europea. Colección Pretextos 39. 2010. 